\title{
Percutaneous Patent Foramen Ovale Closure versus Medical Therapy in Cryptogenic Stroke: An Update Meta-Analysis of Randomized Controlled Trials
}

\author{
Xiaohui Luo, Dandan Yan, Hui Shao, Yajuan Du* \\ Department of Structural Heart Disease, The First Affiliated Hospital of Xi'an Jiaotong University, Xi'an, China \\ Email: *xmy505@163.com
}

How to cite this paper: Luo, X.H., Yan, D.D., Shao, H. and Du, Y.J. (2018) Percutaneous Patent Foramen Ovale Closure versus Medical Therapy in Cryptogenic Stroke: An Update Meta-Analysis of Randomized Controlled Trials. World Journal of Cardiovascular Diseases, 8, 411-423. http://dx.doi.org/10.4236/wjcd.2018.88040

Received: July 18, 2018

Accepted: August 12, 2018

Published: August 15, 2018

Copyright $\odot 2018$ by authors and Scientific Research Publishing Inc. This work is licensed under the Creative Commons Attribution-NonCommercial International License (CC BY-NC 4.0). http://creativecommons.org/licenses/by-nc/4.0/ http://creativecommons.org/licens

\begin{abstract}
Objectives: Concerns regarding the real efficacy of transcatheter patent foramen ovale ( $\mathrm{PFO}$ ) closure versus medical therapy in patients with cryptogenic stroke remained unresolved. We performed a meta-analysis using the randomized controlled trials on the efficacy and safety of transcatheter PFO closure in patients with cryptogenic stroke. Methods: Web of Science, EMBASE, PubMed, and the Cochrane Library were searched for relevant randomized controlled trials (RCTs). The primary outcome was recurrent stroke and transient-ischemic attack (TIA). Original data, hazard ratio (HR) with $95 \%$ confidence interval $(95 \% \mathrm{CI})$ were abstracted to calculate a pooled effect size. Results: Our meta-analysis showed benefit with device closure when compared with medical therapy with an HR of 0.54 (95\% CI: $0.39-0.74, \mathrm{P}=0.108)$ in the intention-to-treat cohort, 0.44 (95\% CI: 0.24 $0.82, \mathrm{P}=0.103$ ) in the per-protocol populations, and 0.43 (95\% CI: 0.31 $0.60, \mathrm{P}=0.019)$ in the as-treated populations. There was a significantly higher incidence of new-onset atrial fibrillation in PFO closure patients $(\mathrm{OR}=4.53,95 \% \mathrm{CI}: 2.58-7.97, \mathrm{P}=0.094)$. PFO Patients with an atrial septal aneurysm benefit from device closure $(\mathrm{OR}=0.39,95 \% \mathrm{CI}: 0.22-0.69, \mathrm{P}$ $=0.053)$. Patients with a substantial PFO shunt benefit the greatest with device closure with a pooled OR of 0.27 (95\% CI: $0.14-0.56, \mathrm{P}=0.525)$. Conclusions: The meta-analysis concluded that PFO closure was associated with significantly lower risk of recurrent stroke in PFO patients with cryptogenic stroke than with medical therapy alone. The benefit of PFO closure was greater in patients with a substantial shunt and atrial septal aneurysm. PFO closure was associated with higher rates of new-onset atrial fibrillation.
\end{abstract}




\section{Keywords}

Patent Foramen Ovale, Transcatheter Closure, Medical Therapy, Cryptogenic Stroke, Meta-Analysis

\section{Introduction}

The patent foramen ovale (PFO) is a critical communication of the normal fetal circulation; however, it continues to remain patent after birth in up to $25 \%$ of adults [1]. Previous studies have found a prevalence of up to $66 \%$ of PFO in patients with cryptogenic stroke as compared with $27 \%$ in patients with stroke from known causes [2]. The cause of stroke without identifiable aetiology in PFO patients might be paradoxical thromboembolism [3]. Epidemiologic study has found a significant association between PFO and cryptogenic stroke both in the younger and older patients [3] [4]. It was reported that the incidence of stroke recurrence in PFO patients after medical therapy within a four-year follow-up period was approximately 25\% [5]. Percutaneous PFO closure has been available over the past two decades without compelling evidence to guide patients and device selection [6]. Therefore, there has been a growing debate on whether percutaneous closure of PFO was to medical therapy. However, results from previous published RCTs failed to show superiority of device closure over medical therapy in the intention to treat cohort [7] [8] [9]. Several meta-analyses of RCTs derived from the three trials concluded results strikingly discordant with each other [6] [10] [11] [12] [13]. The major limitation of these meta-analyses was the small number of events during the follow-up, with little sufficiently powered to show the difference in primary end-point. Recently, 3 recent randomized controlled trials have concluded that use of PFO closure devices was associated with a lower risk of recurrent stroke than that observed with medical treatment [14] [15] [16]. Therefore, an update meta-analysis that involved the role of percutaneous PFO closure versus medical therapy in cryptogenic stroke is urgently warranted.

\section{Methods}

\subsection{Data Sources and Search Strategy}

We performed a systematic literature search of PubMed, Embase, Web of Science, and Cochrane Library from inception to October 4, 2017. The meta-analysis was conducted according to the PRISMA (Preferred Reporting Items for Systematic Reviews and Meta-Analyses) guidelines [17]. The search terms included "patent foramen ovale", "PFO", "atrial septal aneurysm", "right to left shunt", "interatrial shunt", "stroke", "ischemic stroke", "cryptogenic stroke", "recurrent stroke", "recurrent thromboembolism", "recurrent TIA", "transient ischemic attack", "TIA", "brain infarction", "cryptogenic embolism", "medical 
therapy", "antiplatelet", "anticoagulants", "platelet aggregation", "transcatheter closure", "percutaneous closure", "cardiac catheterization", "intervention study", and "randomized controlled trial" which were searched as text word and as exploded medical subject headings when available. No language restrictions were imposed in either the search process or study selection. To identify further papers, reference lists from each article were also scanned for appropriate studies. Also, any disagreement was solved by a third expert researcher.

\subsection{Inclusion Criteria and Data Extraction}

A study was included in the meta-analysis if it met the following criteria: 1) Original studies reported the population of PFO patients with cryptogenic stroke/TIA; 2) Study results focused on comparison of medical therapy versus transcatheter PFO closure in patients with cryptogenic stroke; and 3) The design of clinical trial is based on randomized controlled trial. Two experience reviewers independently performed the data extraction according to a pre-defined data extraction form and any disagreements were resolved by discussion among all authors. Extracted data included the following: first author's name, study acronym, year of study, the total sample size, the place of study, type of medical therapy or device used, hazard ratio and $95 \%$ confidence intervals in each study of stroke/TIA, primary endpoint, and secondary endpoint.

\subsection{Outcome Measures and Quality Assessment}

The primary outcome was a composite of recurrent stroke, TIA or adverse event, including new-onset atrial fibrillation, major bleeding episode, during the follow up period. Sub-group analysis was performed with respect to the Amplatzer occluder device alone, atrial septal aneurysm, and shunt size. All investigators independently evaluated methodological quality of the included studies using the Cochrane Collaboration's tool of risk of bias for RCTs [18]. Six items, including random sequence generation; allocation concealment; blinding; incomplete outcome data; selective reporting; and other biases, were judged as low risk, unclear risk, or high risk in every study, respectively. Any disagreements were resolved by discussion among all authors.

\subsection{Statistical Analysis}

All statistical analyses were carried out with Stata version 11.0 software (StataCorp, College Station, TX). Hazard Ratio (HR) or Odds Ratio (OR) with 95\% confidence interval (95\% CI) was used to estimate the effect sizes. I-squared $\left(\mathrm{I}^{2}\right)$ statistical tests were used to explore the statistical heterogeneity among studies. There was no statistical heterogeneity when $\mathrm{I}^{2}<50 \%$, and a fixed-effects model was used; otherwise, statistical heterogeneity was existed, and a random-effects model was adopted [19]. Subgroup analysis was also conducted when related data available. Egger's test was to evaluate the possible publication bias, and a $\mathrm{P}$ value of $<0.05$ indicates potential publication bias. 


\section{Results}

\subsection{Search Results and Characteristic of Included Studies}

Our literature search initially yielded 117 citations. After removing the duplicates records and further screening the titles and the abstracts, 32 papers remained for full text evaluation. 26 of them were excluded by reading full texts. Finally, 6 RCTs were included in this meta-analysis (Figure 1). The combined study involved 4370 participants. Participants were randomized to device closure $(n=2278)$ and medical therapy $(n=2092)$, respectively. Characteristics of 6 eligible studies are shown in Table 1 . These included trials were all multicentric and mainly performed in Europe and America. The years of publication ranged from 2012 to 2017. The follow-up duration ranged from 2 years to median of 5.9 years. The primary endpoint mainly focused on recurrence of ischemic stroke and TIA. The overall methodological quality assessment results of six RCTs are relatively good. All 6 trials were open-label studies and had a "high" risk of bias with respect to blinding of participants and personnel. It is impossible to blind of participants in this situation (Table 2).

\subsection{Meta-Analysis of Primary Outcomes}

A total of 4370 PFO patients with a prior history of cryptogenic stroke were randomized divided into device closure group (2278 participants) and medical therapy group (2092 participants). The meta-analysis found that device closure was superior to medical treatment in the prevention of strokes and/or TIA in PFO patients according to intention to treat population ( $\mathrm{HR}=0.54,95 \% \mathrm{CI}: 0.39$ - 0.74, $\left.\mathrm{I}^{2}=44.7 \%, \mathrm{P}=0.108\right)$. The pooled HR was 0.52 (95\% CI: $0.35-0.77, \mathrm{I}^{2}=$

117 potential records identified through related database searching

48 duplicates records removed

69 papers screened for eligibility

37 papers excluded after reading abstract

6 randomized controlled trials included in quantitative synthesis (meta-analysis)

Figure 1. Flow chart of study selection process in the meta-analysis. 
Table 1. Characteristics of six studies included in the meta-analysis.

\begin{tabular}{|c|c|c|c|c|c|c|c|c|c|c|}
\hline $\begin{array}{l}\text { First } \\
\text { author }\end{array}$ & $\begin{array}{l}\text { Study } \\
\text { acronym }\end{array}$ & $\begin{array}{l}\text { Publication } \\
\text { year }\end{array}$ & Country & Participants & Follow-up & HR (95\% CI) & Device closure & Medical therapy & $\begin{array}{l}\text { Primary } \\
\text { endpoint }\end{array}$ & $\begin{array}{l}\text { Secondary } \\
\text { endpoint }\end{array}$ \\
\hline $\begin{array}{l}\text { Meier } \\
\text { et al. }\end{array}$ & PC & 2013 & $\begin{array}{l}\text { Europe, } \\
\text { Canada, } \\
\text { Brazil, and } \\
\text { Australia }\end{array}$ & 414 & $\begin{array}{l}4.1 \text { years in the } \\
\text { closure group } \\
\text { and } 4.0 \text { years in } \\
\text { the } \\
\text { medical-therapy } \\
\text { group }\end{array}$ & $\begin{array}{l}0.63 \\
(0.24-1.62)\end{array}$ & $\begin{array}{l}\text { Amplatzer PFO } \\
\text { Occluder }\end{array}$ & $\begin{array}{l}\text { Antiplatelet } \\
\text { therapy or oral } \\
\text { anticoagulation }\end{array}$ & $\begin{array}{l}\text { Nonfatal stroke, } \\
\text { TIA, peripheral } \\
\text { embolism, and } \\
\text { all-cause } \\
\text { mortality }\end{array}$ & $\begin{array}{l}\text { Cardiovascular } \\
\text { death, new } \\
\text { arrhythmias, } \\
\text { myocardial } \\
\text { infarction, } \\
\text { device-related } \\
\text { problems, and } \\
\text { bleeding }\end{array}$ \\
\hline $\begin{array}{l}\text { Furlan } \\
\text { et al. }\end{array}$ & CLOSURE I & I 2012 & $\begin{array}{l}\text { USA and } \\
\text { Canada }\end{array}$ & 909 & 2 years & $\begin{array}{l}0.78 \\
(0.45-1.35)\end{array}$ & $\begin{array}{l}\text { STARFlex septal } \\
\text { closure system }\end{array}$ & $\begin{array}{l}\text { Warfarin, } \\
\text { aspirin or both }\end{array}$ & $\begin{array}{l}\text { Stroke or TIA, } \\
\text { all-cause } \\
\text { mortality, and } \\
\text { death from } \\
\text { neurologic } \\
\text { causes }\end{array}$ & $\begin{array}{l}\text { Major bleeding, } \\
\text { death from any } \\
\text { cause, stroke, } \\
\text { TIA, and } \\
\text { transient } \\
\text { neurologic } \\
\text { events of } \\
\text { uncertain cause }\end{array}$ \\
\hline $\begin{array}{l}\text { Mas } \\
\text { et al. }\end{array}$ & CLOSE & 2017 & $\begin{array}{l}\text { France and } \\
\text { Germany }\end{array}$ & 663 & $5.3 \pm 2.0$ years & $\begin{array}{l}0.55 \\
(0.31-0.999)\end{array}$ & $\begin{array}{l}\text { Eleven different } \\
\text { devices }\end{array}$ & $\begin{array}{l}\text { aspirin, } \\
\text { clopidogrel, or } \\
\text { aspirin with } \\
\text { dipyridamole }\end{array}$ & $\begin{array}{l}\text { Recurrence of } \\
\text { fatal or nonfatal } \\
\text { stroke }\end{array}$ & $\begin{array}{l}\text { Ischemic stroke, } \\
\text { TIA systemic } \\
\text { embolism, } \\
\text { disabling stroke; } \\
\text { ischemic stroke, } \\
\text { all-cause } \\
\text { mortality, } \\
\text { cardiovascular } \\
\text { death }\end{array}$ \\
\hline $\begin{array}{l}\text { Saver } \\
\text { et al. }\end{array}$ & RESPECT & 2017 & $\begin{array}{l}\text { USA and } \\
\text { Canada }\end{array}$ & 980 & $\begin{array}{l}\text { Median of } 5.9 \\
\text { years }\end{array}$ & $\begin{array}{l}0.23 \\
(0.09-0.62)\end{array}$ & $\begin{array}{l}\text { Amplatzer PFO } \\
\text { Occluder }\end{array}$ & $\begin{array}{l}\text { Aspirin, warfarin, } \\
\text { clopidogrel, or } \\
\text { aspirin combined } \\
\text { with dipyridamole }\end{array}$ & $\begin{array}{l}\text { Recurrent } \\
\text { nonfatal } \\
\text { ischemic stroke, } \\
\text { fatal ischemic } \\
\text { stroke, or early } \\
\text { death }\end{array}$ & $\begin{array}{l}\text { Absence of } \\
\text { recurrent } \\
\text { cryptogenic, } \\
\text { early } \\
\text { cardiovascular } \\
\text { death, absence of } \\
\text { transient } \\
\text { ischemic attack }\end{array}$ \\
\hline $\begin{array}{l}\text { Søndergaard } \\
\text { et al. }\end{array}$ & $\begin{array}{l}\text { Gore } \\
\text { REDUCE }\end{array}$ & 2017 & $\begin{array}{l}\text { Canada, } \\
\text { Denmark, } \\
\text { Finland, } \\
\text { Norway, } \\
\text { Sweden, } \\
\text { the UK, } \\
\text { and the } \\
\text { US }\end{array}$ & 664 & $\begin{array}{l}\text { Median of } 3.2 \\
\text { years }\end{array}$ & $\begin{array}{l}0.03 \\
(0-0.26)\end{array}$ & $\begin{array}{l}\text { Helex Septal } \\
\text { Occluder and } \\
\text { Cardioform } \\
\text { Septal Occluder }\end{array}$ & $\begin{array}{l}\text { Aspirin, aspirin } \\
\text { with dipyridamole, } \\
\text { clopidogrel, or } \\
\text { clopidogrel }\end{array}$ & $\begin{array}{l}\text { Recurrent } \\
\text { ischemic } \\
\text { stroke, } \\
\text { all-cause } \\
\text { mortality }\end{array}$ & $\begin{array}{l}\text { New brain } \\
\text { infarction, } \\
\text { success of PFO } \\
\text { closure }\end{array}$ \\
\hline
\end{tabular}

$\mathrm{HR}=$ hazard ratio; TIA = transient-ischemic attack; PFO = patent foramen ovale; RESPECT = randomized evaluation of recurrent stroke comparing PFO closure to established current standard of care treatment; PC Trial = clinical trial comparing percutaneous closure of patent foramen ovale (PFO) using the Amplatzer PFO occluder with medical treatment in patients with cryptogenic embolism; CLOSURE I = evaluation of the STARFlex septal closure system in patients with a stroke and/or transient ischemic attack due to presumed paradoxical embolism through a patent foramen ovale; CLOSE = patent foramen ovale closure or anticoagulants versus antiplatelet therapy to prevent stroke recurrence; Gore REDUCE = comparing antiplatelet medical management plus percutaneous patent foramen ovale device closure to antiplatelet medical management alone. 
Table 2. Risk of bias assessment of six included studies ${ }^{\mathrm{a}}$.

\begin{tabular}{|c|c|c|c|c|c|c|}
\hline Study & $\begin{array}{l}\text { Sequence } \\
\text { generation }\end{array}$ & $\begin{array}{c}\text { Allocation } \\
\text { concealment }\end{array}$ & $\begin{array}{l}\text { Blinding of participants } \\
\text { and personnel and } \\
\text { outcome assessors }\end{array}$ & $\begin{array}{l}\text { Incomplete } \\
\text { outcome data }\end{array}$ & $\begin{array}{l}\text { Selective } \\
\text { outcome } \\
\text { reporting }\end{array}$ & $\begin{array}{c}\text { Other sources } \\
\text { of bias }\end{array}$ \\
\hline Carroll et al. 2013 & Low & Low & $\operatorname{High}^{\mathrm{b}}$ & $\operatorname{High}^{c}$ & Low & Uncertain $^{\mathrm{d}}$ \\
\hline Meier et al. 2013 & Low & Low & $\operatorname{High}^{\mathrm{b}}$ & $\operatorname{High}^{\mathrm{c}}$ & Low & Uncertain $^{\mathrm{d}}$ \\
\hline Furlan et al. 2012 & Low & Low & $\operatorname{High}^{\mathrm{b}}$ & $\operatorname{High}^{\mathrm{c}}$ & Low & Uncertain $^{\mathrm{d}}$ \\
\hline Saver et al. 2017 & Low & Low & $\operatorname{High}^{b}$ & $\operatorname{High}^{c}$ & Low & Uncertain $^{\mathrm{d}}$ \\
\hline Søndergaard et al. 2017 & Low & Low & $\operatorname{High}^{\mathrm{b}}$ & Low & Low & Uncertain $^{\mathrm{d}}$ \\
\hline Mas et al. 2017 & Low & Low & $\operatorname{High}^{\mathrm{b}}$ & $\operatorname{High}^{c}$ & Low & Uncertain $^{\mathrm{d}}$ \\
\hline
\end{tabular}

${ }^{a}$ Each study has been evaluated as being "High", "Low", or "Unclear" according to the Cochrane Collaboration's tool of risk of bias for RCTs. "Low" indicates a study with "Low Risk of Bias"; "High" indicates "High Risk of Bias"; "Unclear" indicates "Unclear Risk of Bias". bUn-blinded, open-labeled. 'Drop-off rate $>10 \%$. ${ }^{\mathrm{d}}$ Conflict of interest, financial supports.

$48.0 \%, \mathrm{P}=0.103)$ using the per-protocol population and was 0.43 (95\% CI: 0.31 - $\left.0.60, \mathrm{I}^{2}=69.9 \%, \mathrm{P}=0.019\right)$ using the as-treated population, which also presenting a beneficial effect of device closure (Figure 2). When assessing stroke alone in intention to treat population, there was an obvious benefit of device closure when compared with medical therapy (pooled HR $=0.49,95 \%$ CI: 0.34 $\left.0.70, \mathrm{I}^{2}=46.2 \%, \mathrm{P}=0.098\right)$. However, when focusing on TIA alone, there was no benefit of device closure when compared with medical therapy (pooled HR = $0.73,95 \%$ CI: $\left.0.49-1.09, \mathrm{I}^{2}=0, \mathrm{P}=0.917\right)$.

\subsection{Secondary Outcomes and Subgroup-Analysis}

New-onset atrial fibrillation/flutter (AF) was observed in 78 of 2282 patients treated with the device closure and in 15 of 2088 patients treated with standard medical therapy. The risk of new-set AF was higher in the device closure group when compared with medical therapy (pooled OR $=4.53,95 \%$ CI: $2.58-7.97, \mathrm{I}^{2}$ $=46.8 \%, \mathrm{P}=0.094$ ) (Figure 3 ). Six studies all reported the adverse event. There was no significant difference with respect to the incidence of any adverse event between device closure group and medical therapy group (pooled OR $=1.05$, 95\% CI: $0.93-1.20, \mathrm{I}^{2}=0, \mathrm{P}=0.802$ ). The incidence of major bleeding episodes was also not significantly different between the 2 groups (pooled OR $=1.05,95 \%$ CI: $\left.0.64-1.75, \mathrm{I}^{2}=32.3 \%, \mathrm{P}=0.194\right)$.

We conducted subgroup analyses to assess whether "high-risk PFO" patients benefited from device closure when compared with medical therapy. Four studies reported substantial right-to-left shunt (RLS) both in device closure group and medical therapy group [8] [9] [15] [16]. There was significant reduction in recurrent stroke between 2 groups $\left(\mathrm{OR}=0.27,95 \% \mathrm{CI}: 0.14-0.56, \mathrm{I}^{2}=0, \mathrm{P}=\right.$ 0.525) (Figure 4(A)). Patients with PFO concomitant with an atrial septal aneurysm (ASA) also benefit from device closure with an OR of 0.39 (95\% CI: 0.22 $0.69, \mathrm{I}^{2}=57.1 \%, \mathrm{P}=0.053$ ) (Figure 4(B)). Analysis of Amplatzer PFO occluder was available in three studies [7] [9] [15]. Similar result was verified when the Amplatzer PFO closure device was analyzed. There was a significant reduction 
X. H. Luo et al.

Study

$\%$

ID

$\mathrm{HR}(95 \% \mathrm{Cl}) \quad$ Weight

A. Intention to treat cohort

Carroll et al RESPECT (2013)

Meier et al PC (2013)

Furlan et al CLOSURE I (2012)

Saver et al RESPECT (2017)

Sondergaard et al Gore REDUCE (2017)

Mas et al CLOSE (2017)

Subtotal (I-squared $=44.7 \%, p=0.108$ )

B. Per-protocol cohort

Carroll et al RESPECT (2013)

Meier et al PC (2013)

Furlan et al CLOSURE I (2012)

Sondergaard et al Gore REDUCE (2017)

Mas et al CLOSE (2017)

Subtotal (I-squared $=48.0 \%, p=0.103$ )

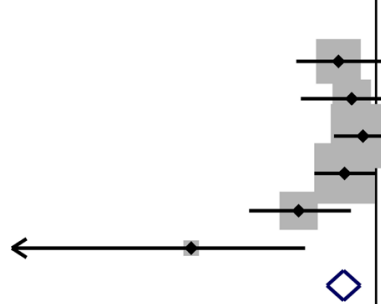

$0.49(0.22,1.11) \quad 15.18$

$0.63(0.24,1.62) \quad 10.90$

$0.78(0.45,1.35) \quad 32.94$

$0.55(0.31,1.00) \quad 29.03$

$0.23(0.09,0.62) \quad 10.67$

$0.03(0.00,0.26) \quad 1.29$

$0.54(0.39,0.74) \quad 100.00$

C. As-treated cohort

Carroll et al RESPECT (2013)

Meier et al PC (2013)

Furlan et al CLOSURE I (2012)

Sondergaard et al Gore REDUCE (2017)

Subtotal (I-squared $=69.9 \%, p=0.019$ )

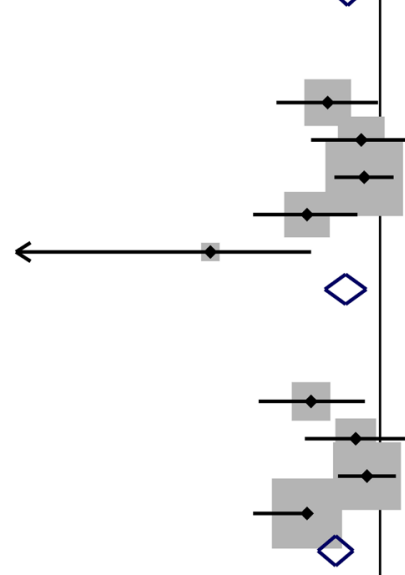

$0.37(0.14,0.96) \quad 16.64$

$0.70(0.27,1.85) \quad 16.65$

$0.74(0.42,1.29) \quad 48.97$

$0.25(0.09,0.65) \quad 15.77$

$0.04(0.00,0.27) \quad 1.97$

$0.52(0.35,0.77) \quad 100.00$

$0.27(0.10,0.75) \quad 11.01$

$0.63(0.24,1.62) \quad 12.26$

$0.78(0.45,1.35) \quad 37.03$

$0.25(0.09,0.26) \quad 39.71$

$0.43(0.31,0.60) \quad 100.00$

Study

ID
OR $(95 \% \mathrm{Cl})$

Figure 2. Forest plot comparing the stroke/transient-ischemic attack of device closure and medical therapy in intention to treat cohort (A), per-protocol cohort (B), and as-treated cohort (C), respectively.

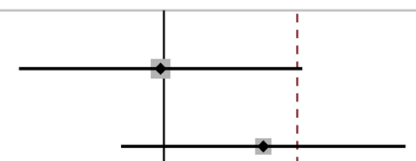

$96(0.19,4.80)$

$3.09(0.62,15.48) \quad 6 / 210 \quad 2 / 212 \quad 12.93$

$8.73(2.60,29.31) \quad 23 / 425 \quad 3 / 461 \quad 18.20$

$1.45(0.41,5.16) \quad 6 / 505 \quad 4 / 485 \quad 26.96$

$14.66(1.98,108.35) \quad 29 / 470 \quad 1 / 224 \quad 8.50$

$\begin{array}{llll}5.43(1.19,24.77) & 11 / 249 & 2 / 237 & 13.10\end{array}$

$4.53(2.58,7.97) \quad 78 / 2361 \quad 15 / 2103 \quad 100.00$

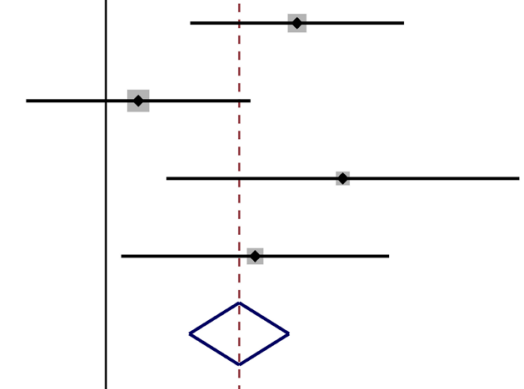

Overall (I-squared $=46.8 \%, p=0.094$

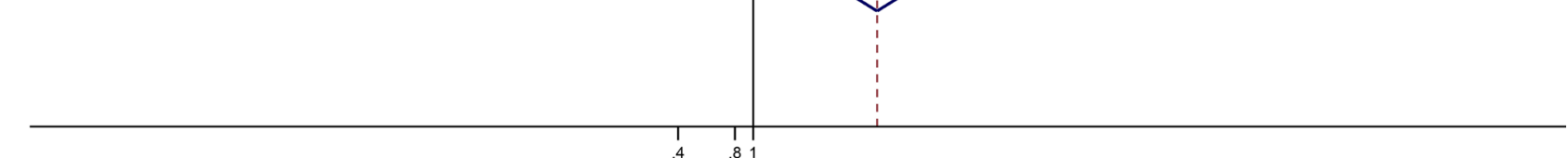

Figure 3. Forest plot of six randomized controlled trial comparing new-onset atrial fibrillation between patent foramen ovale device closure and medical treatment. 
Study

ID
Events, Events, \%

OR $(95 \% \mathrm{Cl})$ closure threapy Weight

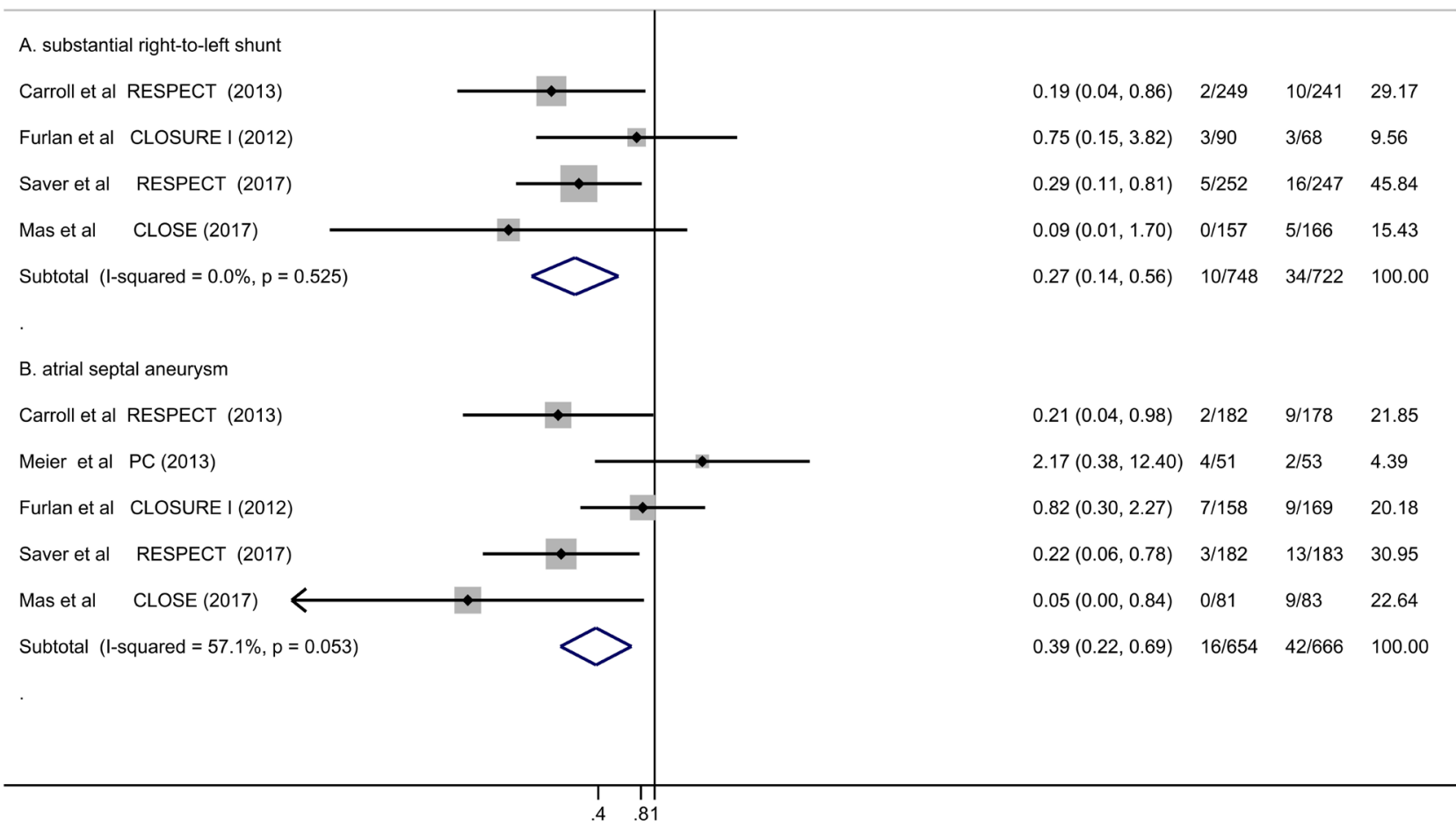

Figure 4. Forest plot comparing the substantial right-to-left shunt of device closure and medical therapy (A); Forest plot comparing the atrial septal aneurysm of device closure and medical therapy (B).

in recurrent cryptogenic strokes (combined $\mathrm{HR}=0.55,95 \% \mathrm{CI}=0.36-0.84, \mathrm{I}^{2}=$ $0 \%, \mathrm{P}=0.925)$ in the Amplatzer PFO closure group compared with medical therapy alone.

\subsection{Sensitivity Analysis and Publication Bias}

Sensitivity analysis was performed by removing a single study on the overall $\mathrm{HR} / \mathrm{OR}$ at a time. The result of sensitivity analysis for total HR/OR in this meta-analysis was not affected by removing the single study which indicated the results had a good stability. To evaluate potential publication bias across six studies, Egger's test with funnel plot asymmetry was used to identify small study effects in this study. The Result for Egger test indicated a low potential publication bias $(\mathrm{P}=0.462)$.

\section{Discussion}

In this update meta-analysis of six RCTs, we concluded that the PFO device closure was associated with lower risk of recurrent strokes/TIA when compared to standard medical therapy in patients with PFO and cryptogenic stroke. In pooled analyses, the meta-analysis demonstrated that transcatheter PFO device closure is superior to medical therapy in patients with a substantial shunt and patients with PFO concomitant with an atrial septal aneurysm for secondary 
prevention of cryptogenic stroke. The pooled results also demonstrated a benefit effect of Amplatzer PFO device closure in preventing recurrent strokes in PFO patients with cryptogenic stroke.

Previous three randomized controlled trials failed to show the superiority of device closure over standard medical therapy in the prevention of recurrence cryptogenic stroke in patients with PFO [7] [8] [9]. Two studies show a tendency to benefit from PFO device closure with nonsignificant of HR of 0.20 (95\% CI: 0.02 - 1.72) [9] and 0.49 (95\% CI: 0.22 - 1.11) [7]. Previous meta-analysis derived from the three above RCTs also indicated that there was a potential benefit effect from device closure in reducing the incidence of recurrence stroke [6] [12] [13] [20]. Moreover, some authors argued that there was no sufficient evidence to favor benefit or harm [21] [22]. There was no overwhelming evidence or consensus with respect to on the safety and effectiveness of PFO device closure for preventing a recurrent ischemic stroke. The first randomized controlled trial of PFO closure using STARFlex device, CLOSURE I, failed to show superiority of device closure over medical therapy for preventing recurrent ischemic stroke [8]. The study was criticized for suboptimal rate of effective PFO closure in device closure group. Among 366 patients from the device closure group performed transesophageal echocardiography at follow-up of 6 months, 51 (14\%) patients were documented significant residual right-to-left shunt. Besides, 909 enrolled patients involved stroke and TIA, while TIA was used as an endpoint, which was a confounding factor. Both of stroke and TIA will present a negative magnetic resonance imaging study; therefore, it is very difficult to distinguish them by imaging techniques. It is challenging to interpret the results by combining stroke and TIA together in the endpoint. In this study, when assessing stroke alone in intention-to-treat cohort, we yielded a positive result with an HR of 0.43 (95\% CI: 0.25 - 0.76). However, we failed to confirm this association when assess TIA alone (HR: $0.73,95 \%$ CI: 0.49 - 1.09). The second randomized controlled trial performed in the United States, RESPECT, using the Amplatzer PFO device for preventing recurrent ischemic stroke [9]. The primary endpoint analysis was conducted after a mean follow-up of 3.0 years in the PFO closure group and 2.7 years in the medical therapy group. However, the difference between device closure group and medical treatment group still did not reach statistical significance $(P=0.089)$. The extended follow-up of the RESPECT trial showed a lower rate of recurrent ischemic strokes in PFO device closure patients when compared to medical therapy alone during extended follow-up [15]. The main difference between the previous study and the extended follow-up study was that the follow-up duration of a median of 2.1 years in the previous study [9] and a median of 5.9 years in the extended follow-up [15]. The longer follow-up duration alone, however, may not account for the result changed from negative to positive consequence, as indicated in the PC trial [7]. In PC trial, the primary endpoint was still negative even the mean duration of follow-up as long as 4 years. 
Two recently completed pivotal randomized controlled trials also demonstrated reduced a risk of recurrent stroke after PFO device closure when compared to medical therapy in patients with cryptogenic stroke [14] [16]. A stringent entry criterion was applied to CLOSE trial, which allowed the inclusion of patients who have a substantial right-to-left at rest or an atrial septal aneurysm [16]. This conclusion was further confirmed in the meta-analysis. In our study, we found that patients with PFO concomitant with an ASA and patients with a substantial PFO shunt both benefit greatest from device closure. This indicated that PFO patients with high-risk factors are more likely to facilitate paradoxical embolism to occur [23]; therefore, the effect of PFO device closure becomes convincing. Thus, when determining to conduct the PFO device closure, it's important for clinicians to select appropriate patients. In the RESPECT, PC trials, CLOSURE I, patients with small to moderate RLS accounted for 39\%, 77\%, and $82 \%$, respectively, while majority patients in Gore REDUCE study experienced PFO with moderate-to-extensive RLS [14]. Perhaps that is the reason why two recent trials attained positive results. Risk of total adverse events and major bleeding was similar in six trials, which were further confirmed by the meta-analysis results. However, we also found that PFO device closure was associated with higher rates of new-onset atrial fibrillation. Atrial fibrillation was commonly reported within one month after the procedure and usually transient [14]. The exact clinical mechanism of post-closure atrial fibrillation related to device closure remains uncertain, which requires further investigation [14] [16].

The study concluded that transcatheter device closure is superior to medical therapy for secondary prevention of stroke in patients with cryptogenic stroke and a PFO. However, in fact, current guidelines from the American Heart Association do not disapprove PFO device closure in prevention of cryptogenic stroke or TIA only when a deep venous thrombosis is confirmed [24]. Current American Stroke Association clinical guideline treated the evidence level of PFO device closure in patients with cryptogenic stroke and PFO as "Class IIb; Level of Evidence C" due to inadequate study data [25]. Future guidelines should recommend PFO device closure as first line therapy for secondary prevention of cryptogenic stroke in PFO patients, especially patients with substantial shunt and ASA. However, the study also had limitations. Medical treatment was not uniform across the six trials, which may have a certain effect on outcome events. Besides, it is necessary to mention that some subgroup results had moderate heterogeneity. Clinical heterogeneity among studies with respect to inclusion criteria, study design, follow-up duration, and type of closure device or drugs used highlights the diversity among trials.

\section{Conclusion}

Our meta-analysis of six randomized studies indicates that PFO device closure is associated with significantly lower risk of recurrent stroke in patients with cryptogenic stroke and PFO when compared with medical treatment alone. The ben- 
efit of device closure is greater in patients with a large degree of shunt and atrial septal aneurysm. However, the incidence of new-onset atrial fibrillation is relatively high as indicated by this study.

\section{Disclosure of Grants or Other Funding}

No financial assistance was required for this study.

\section{Authors' Contributions}

Yajuan Du conceived and designed the study; Xiaohui Luo collected the data; Hui Shao and Dandan Yan analyzed the data; Yajuan Du and Xiaohui Luo contributed to the writing of the manuscript.

\section{Conflicts of Interest}

We declare no conflicts of interest.

\section{References}

[1] Drighil, A., El Mosalami, H., Elbadaoui, N., Chraibi, S. and Bennis, A. (2007) Patent Foramen Ovale: A New Disease? International Journal of Cardiology, 122, 1-9. https://doi.org/10.1016/j.ijcard.2006.12.028

[2] Khairy, P., O’Donnell, C.P. and Landzberg, M.J. (2003) Transcatheter Closure versus Medical Therapy of Patent Foramen Ovale and Presumed Paradoxical Thromboemboli: A Systematic Review. Annals of Internal Medicine, 139, 753-760. https://doi.org/10.7326/0003-4819-139-9-200311040-00010

[3] Handke, M., Harloff, A., Olschewski, M., Hetzel, A. and Geibel, A. (2007) Patent Foramen Ovale and Cryptogenic Stroke in Older Patients. The New England Journal of Medicine, 357, 2262-2268. https://doi.org/10.1056/NEJMoa071422

[4] Handke, M., Harloff, A., Bode, C. and Geibel, A. (2009) Patent Foramen Ovale and Cryptogenic Stroke: A Matter of Age? Seminars in Thrombosis and Hemostasis, 35 505-514. https://doi.org/10.1055/s-0029-1234146

[5] Homma, S., Sacco, R.L., Di Tullio, M.R., Sciacca, R.R. and Mohr, J.P. (2002) Effect of Medical Treatment in Stroke Patients with Patent Foramen Ovale: Patent Foramen Ovale in Cryptogenic Stroke Study. Circulation, 105, 2625-2631. https://doi.org/10.1161/01.CIR.0000017498.88393.44

[6] Nagaraja, V., Raval, J., Eslick, G.D., Burgess, D. and Denniss, A.R. (2013) Is Transcatheter Closure Better than Medical Therapy for Cryptogenic Stroke with Patent Foramen Ovale? A Meta-Analysis of Randomised Trials. Heart, Lung and Circulation, 22, 903-909. https://doi.org/10.1016/j.hlc.2013.07.022

[7] Meier, B., Kalesan, B., Mattle, H.P., Khattab, A.A., Hildick-Smith, D., Dudek, D., Andersen, G., Ibrahim, R., Schuler, G., Walton, A.S., Wahl, A., Windecker, S. and Juni, P. (2013) Percutaneous Closure of Patent Foramen Ovale in Cryptogenic Embolism. The New England Journal of Medicine, 368, 1083-1091. https://doi.org/10.1056/NEJMoa1211716

[8] Furlan, A.J., Reisman, M., Massaro, J., Mauri, L., Adams, H., Albers, G.W., Felberg, R., Herrmann, H., Kar, S., Landzberg, M., Raizner, A. and Wechsler, L. (2012) Closure or Medical Therapy for Cryptogenic Stroke with Patent Foramen Ovale. The New England Journal of Medicine, 366, 991-999. 
https://doi.org/10.1056/NEJMoa1009639

[9] Carroll, J.D., Saver, J.L., Thaler, D.E., Smalling, R.W., Berry, S., MacDonald, L.A., Marks, D.S. and Tirschwell, D.L. (2013) Closure of Patent Foramen Ovale versus Medical Therapy after Cryptogenic Stroke. The New England Journal of Medicine, 368, 1092-1100. https://doi.org/10.1056/NEJMoa1301440

[10] Ntaios, G., Papavasileiou, V., Makaritsis, K. and Michel, P. (2013) PFO Closure vs. Medical Therapy in Cryptogenic Stroke or Transient Ischemic Attack: A Systematic Review and Meta-Analysis. International Journal of Cardiology, 169, 101-105. https://doi.org/10.1016/j.ijcard.2013.08.058

[11] Riaz, I.B., Dhoble, A., Mizyed, A., Hsu, C.H., Husnain, M., Lee, J.Z., Lotun, K. and Lee, K.S. (2013) Transcatheter Patent Foramen Ovale Closure versus Medical Therapy for Cryptogenic Stroke: A Meta-Analysis of Randomized Clinical Trials. BMC Cardiovascular Disorders, 13, 116. https://doi.org/10.1186/1471-2261-13-116

[12] Kwong, J.S., Lam, Y.Y. and Yu, C.M. (2013) Percutaneous Closure of Patent Foramen Ovale for Cryptogenic Stroke: A Meta-Analysis of Randomized Controlled Trials. International Journal of Cardiology, 168, 4132-4138. https://doi.org/10.1016/j.ijcard.2013.07.077

[13] Rengifo-Moreno, P., Palacios, I.F., Junpaparp, P., Witzke, C.F., Morris, D.L. and Romero-Corral, A. (2013) Patent Foramen Ovale Transcatheter Closure vs. Medical Therapy on Recurrent Vascular Events: A Systematic Review and Meta-Analysis of Randomized Controlled Trials. European Heart Journal, 34, 3342-3352. https://doi.org/10.1093/eurheartj/eht285

[14] Sondergaard, L., Kasner, S.E., Rhodes, J.F., Andersen, G., Iversen, H.K., Nielsen-Kudsk, J.E., Settergren, M., Sjostrand, C., Roine, R.O., Hildick-Smith, D., Spence, J.D. and Thomassen, L. (2017) Patent Foramen Ovale Closure or Antiplatelet Therapy for Cryptogenic Stroke. The New England Journal of Medicine, 377, 1033-1042. https://doi.org/10.1056/NEJMoa1707404

[15] Saver, J.L., Carroll, J.D., Thaler, D.E., Smalling, R.W., MacDonald, L.A., Marks, D.S. and Tirschwell, D.L. (2017) Long-Term Outcomes of Patent Foramen Ovale Closure or Medical Therapy after Stroke. The New England Journal of Medicine, 377, 1022-1032. https://doi.org/10.1056/NEJMoa1610057

[16] Mas, J.L., Derumeaux, G., Guillon, B., Massardier, E., Hosseini, H., Mechtouff, L., Arquizan, C., Bejot, Y., Vuillier, F., Detante, O., Guidoux, C., Canaple, S., Vaduva, C., Dequatre-Ponchelle, N., Sibon, I., Garnier, P., Ferrier, A., Timsit, S., Robinet-Borgomano, E., Sablot, D., Lacour, J.C., Zuber, M., Favrole, P., Pinel, J.F., Apoil, M., Reiner, P., Lefebvre, C., Guerin, P., Piot, C., Rossi, R., Dubois-Rande, J.L., Eicher, J.C., Meneveau, N., Lusson, J.R., Bertrand, B., Schleich, J.M., Godart, F., Thambo, J.B., Leborgne, L., Michel, P., Pierard, L., Turc, G., Barthelet, M., Charles-Nelson, A., Weimar, C., Moulin, T., Juliard, J.M. and Chatellier, G. (2017) Patent Foramen Ovale Closure or Anticoagulation vs. Antiplatelets after Stroke. The New England Journal of Medicine, 377, 1011-1021. https://doi.org/10.1056/NEJMoa1705915

[17] Liberati, A., Altman, D.G., Tetzlaff, J., Mulrow, C., Gotzsche, P.C., Ioannidis, J.P., Clarke, M., Devereaux, P.J., Kleijnen, J. and Moher, D. (2009) The PRISMA Statement for Reporting Systematic Reviews and Meta-Analyses of Studies That Evaluate Healthcare Interventions: Explanation and Elaboration. BMJ, 339, b2700. https://doi.org/10.1136/bmj.b2700

[18] Higgins, J.P., Altman, D.G., Gotzsche, P.C., Juni, P., Moher, D., Oxman, A.D., Savovic, J., Schulz, K.F., Weeks, L. and Sterne, J.A. (2011) The Cochrane Collaboration's Tool for Assessing Risk of Bias in Randomised Trials. BMJ, 343, d5928. 
https://doi.org/10.1136/bmj.d5928

[19] Higgins, J.P. and Thompson, S.G. (2002) Quantifying Heterogeneity in a Meta-Analysis. Statistics in Medicine, 21, 1539-1558. https://doi.org/10.1002/sim.1186

[20] Kent, D.M., Dahabreh, I.J., Ruthazer, R., Furlan, A.J., Reisman, M., Carroll, J.D., Saver, J.L., Smalling, R.W., Juni, P., Mattle, H.P., Meier, B. and Thaler, D.E. (2016) Device Closure of Patent Foramen Ovale after Stroke: Pooled Analysis of Completed Randomized Trials. Journal of the American College of Cardiology, 67, 907-917. https://doi.org/10.1016/j.jacc.2015.12.023

[21] Kitsios, G.D., Thaler, D.E. and Kent, D.M. (2013) Potentially Large Yet Uncertain Benefits: A Meta-Analysis of Patent Foramen Ovale Closure Trials. Stroke, 44, 2640-2643. https://doi.org/10.1161/STROKEAHA.113.001773

[22] Hakeem, A., Marmagkiolis, K., Hacioglu, Y., Uretsky, B.F., Gundogdu, B., Leesar, M., Bailey, S.R. and Cilingiroglu, M. (2013) Safety and Efficacy of Device Closure for Patent Foramen Ovale for Secondary Prevention of Neurological Events: Comprehensive Systematic Review and Meta-Analysis of Randomized Controlled Trials. Cardiovascular Revascularization Medicine, 14, 349-355. https://doi.org/10.1016/j.carrev.2013.08.010

[23] Ropper, A.H. (2017) Tipping Point for Patent Foramen Ovale Closure. The New England Journal of Medicine, 377, 1093-1095. https://doi.org/10.1056/NEJMe1709637

[24] Kernan, W.N., Ovbiagele, B., Black, H.R., Bravata, D.M., Chimowitz, M.I., Ezekowitz, M.D., Fang, M.C., Fisher, M., Furie, K.L., Heck, D.V., Johnston, S.C., Kasner, S.E., Kittner, S.J., Mitchell, P.H., Rich, M.W., Richardson, D., Schwamm, L.H. and Wilson, J.A. (2014) Guidelines for the Prevention of Stroke in Patients with Stroke and Transient Ischemic Attack: A Guideline for Healthcare Professionals from the American Heart Association/American Stroke Association. Stroke, 45, 2160-2236. https://doi.org/10.1161/STR.0000000000000024

[25] Furie, K.L., Kasner, S.E., Adams, R.J., Albers, G.W., Bush, R.L., Fagan, S.C., Halperin, J.L., Johnston, S.C., Katzan, I., Kernan, W.N., Mitchell, P.H., Ovbiagele, B., Palesch, Y.Y., Sacco, R.L., Schwamm, L.H., Wassertheil-Smoller, S., Turan, T.N. and Wentworth, D. (2011) Guidelines for the Prevention of Stroke in Patients with Stroke or Transient Ischemic Attack: A Guideline for Healthcare Professionals from the American Heart Association/American Stroke Association. Stroke, 42, 227-276. https://doi.org/10.1161/STR.0b013e3181f7d043 